\title{
Comparative Analysis of the Complete Chloroplast Genome of Four Endangered Herbals of Notopterygium
}

\author{
Jiao Yang ${ }^{1}$, Ming Yue ${ }^{1}$, Chuan Niu ${ }^{1}$, Xiong-Feng Ma ${ }^{2, *}$ and Zhong-Hu $\mathrm{Li}^{1, *}$ \\ 1 Key Laboratory of Resource Biology and Biotechnology in Western China, Ministry of Education, \\ College of Life Sciences, Northwest University, Xi'an 710069, China; yangjiao0818@163.com (J.Y.); \\ yueming@nwu.edu.cn (M.Y.); 15829726401@163.com (C.N.) \\ 2 State Key Laboratory of Cotton Biology, Institute of Cotton Research, \\ Chinese Academy of Agricultural Sciences, Anyang 455000, China \\ * Correspondence: maxf_caas@163.com (X.-F.M.); lizhonghu@nwu.edu.cn (Z.-H.L.); \\ Tel./Fax: +86-29-8830-2411 (Z.-H.L.)
}

Academic Editor: Aureliano Bombarely

Received: 6 March 2017; Accepted: 5 April 2017; Published: 19 April 2017

\begin{abstract}
Notopterygium H. de Boissieu (Apiaceae) is an endangered perennial herb endemic to China. A good knowledge of phylogenetic evolution and population genomics is conducive to the establishment of effective management and conservation strategies of the genus Notopterygium. In this study, the complete chloroplast (cp) genomes of four Notopterygium species (N. incisum C. C. Ting ex H. T. Chang, N. oviforme R. H. Shan, N. franchetii $\mathrm{H}$. de Boissieu and N. forrestii $\mathrm{H}$. Wolff) were assembled and characterized using next-generation sequencing. We investigated the gene organization, order, size and repeat sequences of the cp genome and constructed the phylogenetic relationships of Notopterygium species based on the chloroplast DNA and nuclear internal transcribed spacer (ITS) sequences. Comparative analysis of plastid genome showed that the $\mathrm{cp}$ DNA are the standard double-stranded molecule, ranging from $157,462 \mathrm{bp}$ (N. oviforme) to 159,607 bp (N. forrestii) in length. The circular DNA each contained a large single-copy (LSC) region, a small single-copy (SSC) region, and a pair of inverted repeats (IRs). The cp DNA of four species contained 85 protein-coding genes, 37 transfer RNA (tRNA) genes and 8 ribosomal RNA (rRNA) genes, respectively. We determined the marked conservation of gene content and sequence evolutionary rate in the $c p$ genome of four Notopterygium species. Three genes ( $p s a I, p s b I$ and $r p o A$ ) were possibly under positive selection among the four sampled species. Phylogenetic analysis showed that four Notopterygium species formed a monophyletic clade with high bootstrap support. However, the inconsistent interspecific relationships with the genus Notopterygium were identified between the cp DNA and ITS markers. The incomplete lineage sorting, convergence evolution or hybridization, gene infiltration and different sampling strategies among species may have caused the incongruence between the nuclear and $\mathrm{cp}$ DNA relationships. The present results suggested that Notopterygium species may have experienced a complex evolutionary history and speciation process.
\end{abstract}

Keywords: chloroplast genome; evolutionary rate; Illumina sequencing; Notopterygium; phylogenetic relationship

\section{Introduction}

Notopterygium H. de Boissieu (Apiaceae) is an endangered perennial herb endemic to China [1]. According to the records of 'Flora of China', six species are included in the genus Notopterygium, N. incisum C. C. Ting ex H. T. Chang, N. oviforme R. H. Shan, N. franchetii H. de Boissieu, N. forrestii 
H. Wolff, N. tenuifolium M. L. Sheh and F. T. Pu and N. pinnatiinvolucellum F. T. Pu and Y. P. Wang. As an important traditional Chinese medicinal plant, the species of Notopterygium are generally used for treating cold headache, rheumatism paralysis, and shoulder joint ache. Meanwhile, N. incisum and N. franchetii also have other pharmacological effects, including anti-inflammation, anti-bacterial, anti-allergic, anti-viral, etc. [2]. Notopterygium species are geographically distributed among mid-to high-elevation regions (1700 to $5000 \mathrm{~m}$ ) and are mainly distributed in the alpine mountains of the Qinghai-Tibetan Plateau and adjacent regions [3]. The previous studies on the Notopterygium species mainly focused on their morphology, anatomy [4], systematics [5], ecology [6] and pharmacognosy [7]. In recent years, excavation, as well as the expansion of human activities and climate oscillations, has resulted in the increasingly declining wild populations of the Notopterygium species. Now, the natural populations of these Notopterygium species are severely fragmented, and need urgent conservation and restoration [8]. A good knowledge of phylogenetic evolution and population genomics is very important to formulate effective conservation and management strategies. In recent years, comparative analysis of the complete chloroplast ( $\mathrm{cp}$ ) genome of different close species has provided a promising method for the study of phylogeny, population dynamics and species evolution [9-11].

In general, the cp genome of angiosperms is a circular molecule of double-stranded DNA ranging from 76 to $217 \mathrm{~kb}$ in size and containing about 130 genes [12-14]. Gene structure, content, and order of the cp DNA are often highly conserved, and generally contain two identical copies of inverted repeats (IRs), separating the large single-copy (LSC) region and the small single-copy (SSC) region [15-17]. The complete cp DNA is useful in plant systematics and evolution research because of its maternal inheritance and conserved structure characteristics [17]. Recently, many sequences of the complete cp genome of higher plants have been reported [18], which were used to study plant molecular identification, population structure, and phylogenetic relationships at low to high taxonomic levels [19-22]. Especially, the comparative analysis of cp genomes among closely related species shows considerable promise for studying the evolutionary history and species conservation and increasing understanding of phylogenetic relationships [23-26].

The traditional method of Sanger sequencing was troublesome, time-consuming and difficult for isolating and sequencing complete cp genome [27]. In recent years, with the rapid development of high-throughput sequencing technology, more and more complete plant $\mathrm{cp}$ DNA sequences have been constructed based on next generation sequencing (NGS) methods [21,22]. Meanwhile, Illumina-based plastid sequencing has been proven to be a valid and cost-effective way to acquire the complete $\mathrm{cp}$ DNA. Many assembled cp DNA of non-model species also have been obtained and employed for the study of differential gene expression, genetic markers development [28], phylogenomics analysis [29], as well as for detecting selection and inferring adaptive evolution within and among angiosperm species [30,31].

In this study, we used an Illumina Miseq sequencing platform to obtain the whole cp DNA sequence of four endangered herbal plants in the genus Notopterygium, N. incisum, N. oviforme, $N$. franchetii and N. forrestii. Then, in order to obtain a comprehensive and deeply understanding of evolutionary relationships and speciation progress, we also sequenced the nuclear internal transcribed spacer (ITS) sequences and constructed the interspecific relationships among Notopterygium species. The comparative analysis of cp DNA and nuclear ITS sequence variations will provide the basic knowledge for study of the complex evolutionary process and phylogeny for these endangered herbal species.

\section{Materials and Methods}

\subsection{Plant Material and DNA Extraction}

For chloroplast genome analyses, fresh leaves of N. incisum, N. oviforme, N. franchetii and N. forrestii were collected in the field in July, 2015. Total genomic DNA of four individuals from four Notopterygium 
species were isolated using modified $4 \times \mathrm{CTAB}$ method [32]. For ITS analyses, the dried leaves of 70 individuals of eight populations from four species were also collected (Supplementary, Table S1).

\subsection{Genome Sequencing, Assembly and Annotation}

After the genomic DNA isolation, approximately 5-10 $\mu \mathrm{g}$ of DNA was sheared, followed by adapter ligation and library amplification. Then, the fragmented DNAs were subjected to Illumina sample preparation, and pair-read sequenced conducted on the Illumina Miseq platform by Novo Gene Bioinformatics Technology Co. Ltd. (Beijing, China). Illumina raw reads (N. incisum SRR5438310, N. oviforme SRR5438311, N. franchetii SRR5436396, and N. forrestii SRR5436275) were firstly quality trimmed using the Trimming function in NGSQCToolkit v2.3.3 [33]. After low quality reads and adapters were dislodged, the clean reads were firstly assembled using MIRA v4.0.2 [34] with the cp genome of closely related species Anthriscus cerefolium (GU456628), Daucus carota (DQ898156) and Petrosilenum crispum (HM596073) as the references. Subsequently, the desirable contigs were further assembled using MITObim-master [35]. To obtain more accurate cp DNA sequences, each species was assembled at least three times using different references, respectively. In addition, we also used the CLC Genomics workbench v6.5 software with the default parameters set (CLG Bio, Aarhus, Denmark) to assemble the raw reads of four Notopterygium species. We conducted a de novo assembly in order to verify the validity and accuracy of assembly results. After assembled, the obtained scaffolds and contigs were aligned and compared to the reference-based assembly. We also checked the assemblies with read mapping and found that they were not forcing the reads into a false structure. Then, the obtained contigs were generated a consensus sequence in the Geneious R8 v8.0.2 (Biomatters Ltd., Auckland, New Zealand). The gaps were filled by realignment of input reads. Meanwhile, some ambiguous regions with low coverage were confirmed by mapped with reference. We also checked the published complete cp genome sequences available for A. cerefolium, P. crispum, and D. carota using the program MAFFT [36].

In addition, in order to further validate the accuracy of assembly results of $\mathrm{cp}$ DNA, we carried out Sanger sequencing of some cp DNA gene regions, e.g., matk, $r b c L$, $t r n S-t r n G$ (with accession numbers: KY924852-KY924863). We found that these newly obtained cp DNA sequences were highly matched with assembled chloroplast genome. Then, the complete cp genome was annotated using the program DOGMA and manually adjusted the start and stop codons in Geneious R8 [37]. Eventually, a circular cp DNA map was drawn with the online program Organellar Genome DRAW v1.1 (OGDRAW) [38]. The newly obtained cp genome of four species, N. incisum, N. oviforme, N. franchetii and N. forrestii were deposited in GenBank under accession number KX808491-KX808494.

\subsection{Genome Repeat, Gene Selective Pressure Analysis, Phylogenetic Analysis}

We determined the four types of repeats among four cp DNA sequences: dispersed, palindromic, tandem and transfer RNA (tRNA) or gene-similar, the first and second types applying the program REPuter [39], the third one applying the online program Tandem Repeats Finder [40], and the fourth type using the manual revision. The relative evolutionary rate of the cp DNA sequence was quantified based on nonsynonymous $(\mathrm{dN})$ and synonymous $(\mathrm{dS})$ substitutions and their ratios $(\omega=\mathrm{dN} / \mathrm{dS})$. $\mathrm{dN}$ and dS were computed according to the LWL85, LPB93 \& LWLm methods [41-43] as implemented in the PAML package v4.7.1 [44] using the F3 $\times 4$ codon-based substitution model. Only codons shared among all cp genomes were compared. $\mathrm{dN}, \mathrm{dS}$ and $\omega$ were calculated for (1) individual protein-coding genes; (2) the combinations of all protein-coding genes; (3) groups of genes with the same functions, e.g., photosynthesis ATP-synthase genes or NADH-dehydrogenase genes [45]. There were six pairwise alignments for each gene region, which contributed to a total of $283 \omega$ values.

In order to detect the interspecific relationships among four Notopterygium species, we also added the ten cp genomes of the Apiaceae family available in GenBank. Five Araliaceae cp genomes were also downloaded as outgroups (Table S2). We used the following six partitions datasets to conduct a maximum likelihood (ML) tree by using the program MEGA v7.0.18 [46]: (A) whole cp genomes; 
(B) all data excluding a IR region; (C) the LSC region; (D) the SSC region; (E) the protein-coding sequences; (F) the IR region. In addition, the nuclear ITS sequences of 8 populations from four Notopterygium species were sequenced. The obtained 15 ITS (KY848833-KY848847) haplotypes were used to construct phylogenetic tree based on Bayesian inference (BI) [47] and ML analyses [48], using Heracleum moellendorffii, Pleurospermum franchetianum and Pleurospermum prattii as outgroup (KY848848-KY848850). Based on the Akaike information criterion (AIC) in jModeltest v2.1.3 [49], the best-fitting models of sequence evolution were GTR+G (ITS) and GTR+G+I (cp genome), respectively.

\subsection{Sequence Divergence Analysis}

The cp DNA rearrangement analyses of four Notopterygium species were performed using Mauve Alignment [50]. In order to show interspecific variation, the alignments of the cp DNA of the four Notopterygium species were visualized by mVISTA and N. incisum as a reference [51]. The percentages of variable characters for coding and noncoding regions were computed based on the method of Zhang et al. [52]. Nucleotide substitutions were counted using MEGA v7.0.18 [46], and indels (insertion/deletion) were manually detected across the cp genomes.

\section{Results}

\subsection{The Overall Features of $c p D N A$ of Four Notopterygium Species}

The assembled reads of four Notopterygium species, arranged from a total of 110,460 reads of $N$. franchetii to 375,226 reads of $N$. incisum (Table S3). The complete cp DNA of the four Notopterygium species was a double-stranded molecule from 157,462 bp of N. oviforme to 159,607 bp of N. forrestii in length. The cp genome had an overall typical quadripartite structure that was similar to the majority of land plant cp genomes, and contained a pair of IR regions (IRa and IRb), one LSC region and one SSC region. The GC contents of the LSC, SSC, IR regions, and the whole cp genome of four species is shown in Table 1 and Figure 1. The cp genomes of N. incisum, N. franchetii and N. forrestii had the same GC content $(37.70 \%)$, N. oviforme had a subtle difference (37.90\%) compared with others. The GC contents of the LSC and SSC regions (35.8 and 31.6\%) of four species were lower than that of the IR regions (43\%). The higher GC percentage in the IR regions was possibly due to the presence of four ribosomal RNA (rRNA) sequences in these regions.

The genome of four plants contained 85 protein-coding, 37 tRNA and eight rRNA genes (Tables 1 and 2). In 85 protein-coding genes, rps12, rps7, ndhB, ycf2, rpl23, rpl2 genes were repeated once. Of all these 130 predicted functional genes, 113 genes were unique, including 79 protein-coding, 30 tRNA genes and four rRNA genes (Figure 1, Tables 1 and 2). 62 protein-coding and 22 tRNA genes were included in LSC region, whereas SSC region comprised 12 protein-coding and one tRNA genes, $y c f 1$ gene was located in the SSC and IRb region. Meanwhile, nine protein-coding and seven tRNA genes were repeated in the IR regions. In addition, in all these 130 genes, 51 fragments were related to self-replication (four in rRNA and 21 in tRNA), 12 genes related to small subunits of ribosome, nine genes related to large subunits of ribosome and four genes related to DNA-dependent in RNA polymerase subunits, infA gene were related to translational initiation factor. In addition, 46 genes were associated with photosynthesis, including six genes associated with ATP synthase, 11 with NADH oxidoreductase, six with subunits of cytochrome, seven with subunits of photosystem I, and one encoding the $r b c L$ gene. In addition, there were five other genes: matk encoding Maturase, $c e m A$ encoding envelope membrane protein, $a c c D$ encoding subunit of acetyl-CoA, $\operatorname{css} A$ encoding C-type cytochrome synthesis gene, and $c l p P$ encoding Protease (Table 2). 
Table 1. The features of chloroplast genomes of four Notopterygium species.

\begin{tabular}{ccccccccc}
\hline Species & Size (bp) & LSC (bp) & SSC (bp) & IR (bp) & $\begin{array}{c}\text { Number of } \\
\text { Protein-Coding } \\
\text { Genes }{ }^{\mathbf{a}}\end{array}$ & $\begin{array}{c}\text { Number } \\
\text { of tRNA } \\
\text { Genes }\end{array}$ & $\begin{array}{c}\text { Number } \\
\text { of rRNA } \\
\text { Genes }{ }^{\mathbf{a}}\end{array}$ & $\begin{array}{c}\text { GC } \\
\text { Content } \\
\mathbf{( \% )}\end{array}$ \\
\hline N. incisum & 158,684 & 88,260 & 18,232 & 26,096 & $85(6)$ & $37(7)$ & $8(4)$ & 37.70 \\
N. oviforme & 157,462 & 87,304 & 17,996 & 26,081 & $85(6)$ & $37(7)$ & $8(4)$ & 37.90 \\
N. franchetii & 159,389 & 88,749 & 18,290 & 26,175 & $85(6)$ & $37(7)$ & $8(4)$ & 37.70 \\
N. forrestii & 159,607 & 88,870 & 18,212 & 26,262 & $85(6)$ & $37(7)$ & $8(4)$ & 37.70 \\
\hline
\end{tabular}

a The numbers in parenthesis indicate the genes duplicated in the IR regions. LSC: large single-copy; SSC: small single copy; IR: inverted repeats; tRNA: transfer RNA; rRNA: ribosomal RNA.

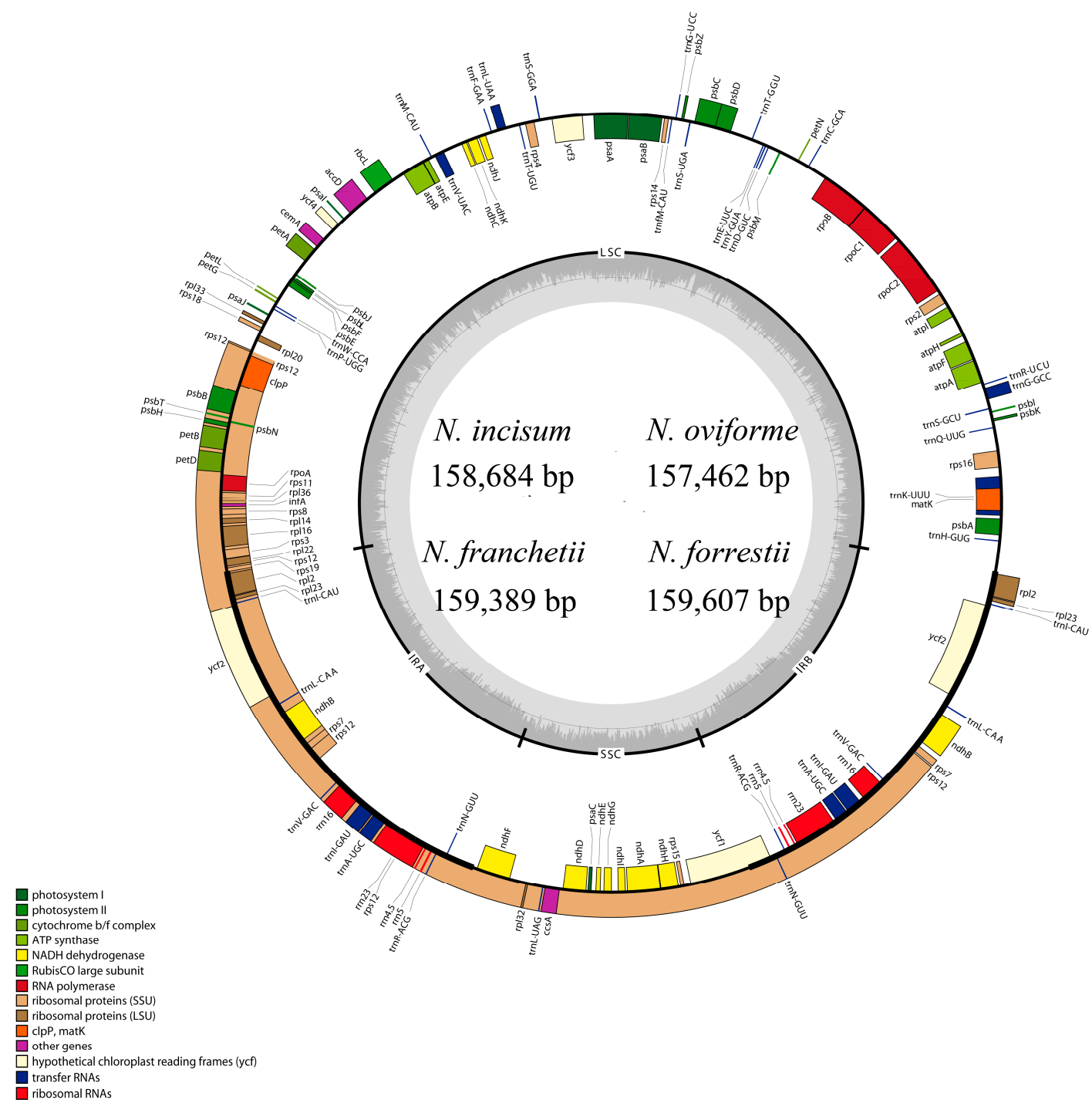

Figure 1. Gene map of four Notopterygium species. Genes lying outside of the outer layer circle are transcribed in the counter clockwise direction, whereas genes inside are transcribed in the clockwise direction. The colored bars indicate known different functional groups. The darker gray area in the inner circle denotes GC content while the lighter gray corresponds to AT content of the genome. LSC: large single copy, SSC: small-single-copy, IR: inverted repeat. 
Table 2. List of genes present in Notopterygium chloroplast genomes.

\begin{tabular}{|c|c|c|c|c|c|c|}
\hline Category & Gene Group & & & Gene Name & & \\
\hline \multirow{6}{*}{ Self-replication } & Ribosomal RNA genes & $\operatorname{rrn16}$ & $r r n 23$ & $r r n 4.5$ & $r r n 5$ & \\
\hline & Transfer RNA genes & $\begin{array}{c}\text { trnI-CAU(2) } \\
\text { trnR-UCU } \\
\text { trnV-UAC } \\
\text { trnP-UGG } \\
\text { trnS-UGA } \\
\text { trnE-UUC }\end{array}$ & $\begin{array}{l}\operatorname{trnI} I-G A U(2) \\
\operatorname{trn} R-A C G(2) \\
\operatorname{trn} V-G A C(2) \\
\operatorname{trnfM} M-C A U \\
\operatorname{trnS}-G C U \\
\operatorname{trn} Y-G U A \\
\end{array}$ & $\begin{array}{l}\operatorname{trnL}-U A A \\
\operatorname{trn} A-U G C(2) \\
\operatorname{trn} F-G A A \\
\operatorname{trn} G-U C C \\
\operatorname{trn} D-G U C \\
\operatorname{trn} Q-U U G\end{array}$ & $\begin{array}{l}\operatorname{trn} L-C A A(2) \\
\operatorname{trn} W-C C A \\
\operatorname{trn} T-U G U \\
\operatorname{trn} G-G C C \\
\operatorname{trn} C-G C A \\
\operatorname{trn} K-U U U\end{array}$ & $\begin{array}{c}\text { trnL-UAG } \\
\text { trnM-CAU } \\
\text { trnT-GGU } \\
\text { trnS-GGA } \\
\text { trnN-GUU(2) } \\
\text { trnH-GUG }\end{array}$ \\
\hline & Small subunit of ribosome & $\begin{array}{l}r p s 2 \\
r p s 11 \\
r p s 18\end{array}$ & $\begin{array}{l}r p s 3 \\
r p s 12 \\
r p s 19\end{array}$ & $\begin{array}{c}r p s 4 \\
r p s 14\end{array}$ & $\begin{array}{c}r p s 7 \\
r p s 15\end{array}$ & $\begin{array}{c}r p s 8 \\
r p s 16\end{array}$ \\
\hline & Large subunit of ribosome & $\begin{array}{c}r p 12 \\
r p 123\end{array}$ & $\begin{array}{l}r p 114 \\
r p 132\end{array}$ & $\begin{array}{l}r p 116 \\
r p 133\end{array}$ & $\begin{array}{l}r p 120 \\
r p 136\end{array}$ & $r p 122$ \\
\hline & DNA-dependent RNA polymerase & rpoA & $r p o B$ & rpoc1 & rpoc2 & \\
\hline & Translational initiation factor & $\inf A$ & & & & \\
\hline \multirow{5}{*}{$\begin{array}{c}\text { Genes for } \\
\text { photosynthesis }\end{array}$} & Subunits of photosystem I & $\begin{array}{l}p s a A \\
y c f 3\end{array}$ & $\begin{array}{l}p s a B \\
y c f 4\end{array}$ & $p s a C$ & psaI & $p s a J$ \\
\hline & Subunits of photosystem II & $\begin{array}{l}p s b A \\
p s b F \\
p s b L\end{array}$ & $\begin{array}{l}p s b B \\
p s b H \\
p s b M\end{array}$ & $\begin{array}{l}p s b C \\
p s b I \\
p s b N\end{array}$ & $\begin{array}{l}p s b D \\
p s b J \\
p s b T\end{array}$ & $\begin{array}{l}p s b E \\
p s b K \\
p s b Z\end{array}$ \\
\hline & $\mathrm{NADH}$ oxidoreductase & $\begin{array}{l}n d h A \\
n d h F \\
n d h K\end{array}$ & $\begin{array}{l}n d h B \\
n d h G\end{array}$ & $\begin{array}{l}n d h \mathrm{C} \\
n d h \mathrm{H}\end{array}$ & $\begin{array}{l}n d h D \\
n d h I\end{array}$ & $\begin{array}{l}n d h E \\
n d h J\end{array}$ \\
\hline & Subunits of cytochrome & $\begin{array}{l}\text { petA } \\
\operatorname{pet} N\end{array}$ & pet $B$ & petD & pet $G$ & petL \\
\hline & $\begin{array}{c}\text { Subunits of ATP } \\
\text { synthase } \\
\text { Large subunit of Rubisco }\end{array}$ & $\begin{array}{l}\operatorname{atpA} \\
\operatorname{atpI} \\
r b c L\end{array}$ & $\operatorname{atp} B$ & $\operatorname{atp} E$ & atpF & $\operatorname{atpH}$ \\
\hline \multirow{5}{*}{ Other genes } & Maturase & matk & & & & \\
\hline & Envelope membrane protein & $\operatorname{cem} A$ & & & & \\
\hline & Subunit of acetyl-CoA & $a c c D$ & & & & \\
\hline & C-type cytochrome synthesis gene & $\cos A$ & & & & \\
\hline & Protease & $\operatorname{clp} P$ & & & & \\
\hline $\begin{array}{l}\text { Conserved } \\
\text { reading frames }\end{array}$ & Conserved Open Reading Frames & $y c f 1$ & $y c f 2$ & & & \\
\hline
\end{tabular}

\subsection{Comparisons of cp DNA of four Notopterygium Species}

The cp genomes of four Notopterygium species were relatively conserved (Figure 2), and no rearrangement occurred in gene organization after verification (Figure 3). The cp DNA size of N. incisum was 158,684 bp in length, and the length of $N$. oviforme was shorter than N. incisum, being 157,462 bp in length. The cp genome size of $N$. franchetii and $N$. forrestii were $159,389 \mathrm{bp}, 159,607 \mathrm{bp}$ respectively. Additionally, the lengths of the LSC varied in four species, from $87,304 \mathrm{bp}$ of $N$. oviforme to $88,870 \mathrm{bp}$ of $N$. franchetii (Table 1). In this region, 62 protein-coding and 22 tRNA genes were included; a complete rps19 gene resided in the LSC of N. oviforme, while it has varying lengths in the LSC/IRb junctions among different species. (e.g., $55 \mathrm{bp}, 46 \mathrm{bp}$ and $154 \mathrm{bp}$ in N. incisum, N. franchetii and N. forrestii respectively). Furthermore, rps19 gene was located between the edges of LSC and IRb regions in $N$. incisum, N. franchetii and N. forrestii. However, in N. oviforme cp genome, rps19 gene was completely located in LSC region and had an 89 bp distance to the edges of LSC. Meanwhile, the lengths of the SSC ranged from $17,996 \mathrm{bp}$ of $N$. oviforme to $18290 \mathrm{bp}$ of $N$. franchetii. It comprised 12 protein-coding and one tRNA gene, $y c f 1$ gene across SSC and IRb region. The minimum (26,081 bp) and maximum length $(26,262 \mathrm{bp})$ of IR regions were located in $N$. oviforme and $N$. franchetii respectively (Table 1$)$. Nine protein-coding and seven tRNA genes were repeated in the IR regions. Compared with other three species, the GC content $(37.90 \%)$ of $N$. oviforme cp genome was slightly higher $(37.90 \%>37.70 \%)$ (Tables 1 and 3). 

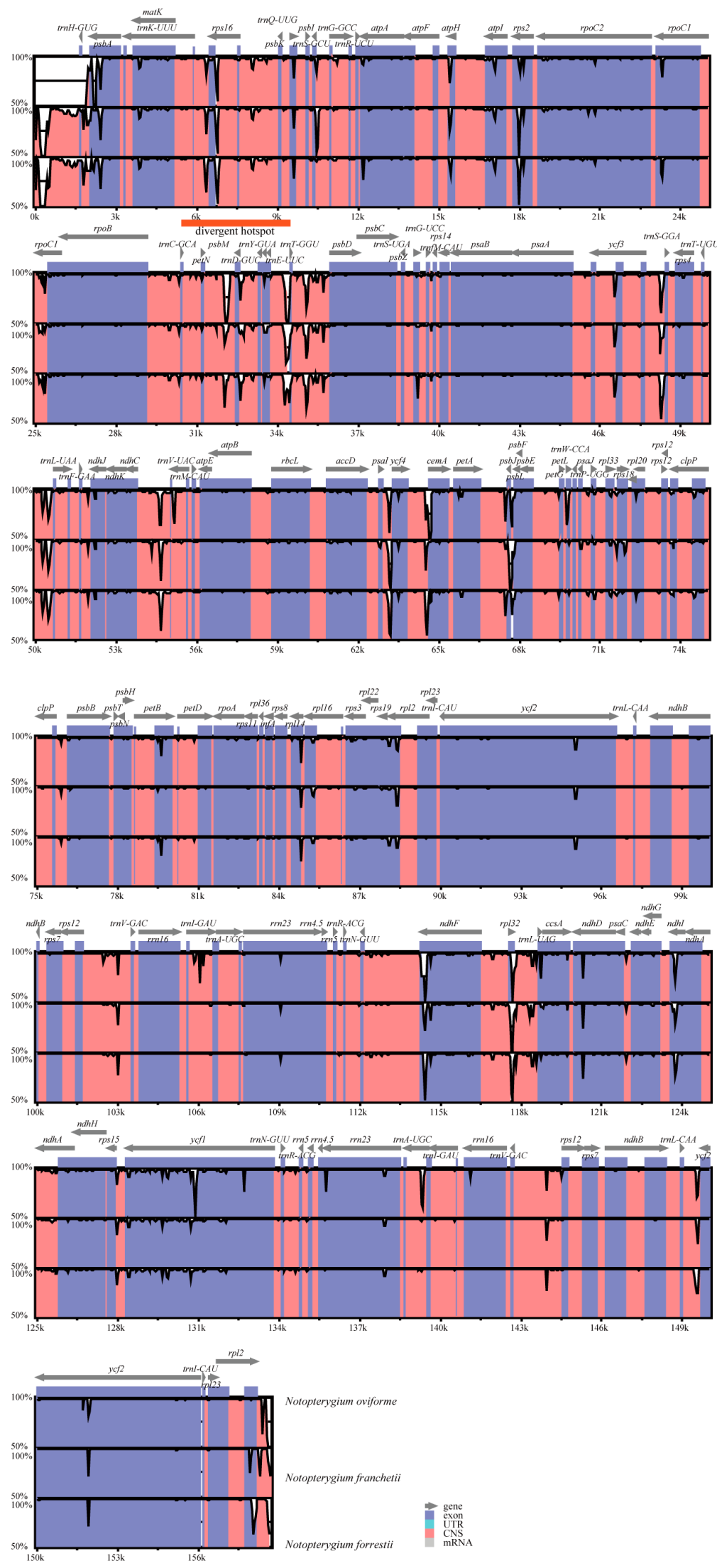

Figure 2. Sequence alignment of chloroplast ( $c p)$ genomes of four Notopterygium species. VISTA-based identity plots showing identity between four Notopterygium species cp genomes, with $N$. incisum as a reference. Genome regions are color coded as protein coding, rRNA coding, tRNA coding or conserved noncoding sequences. The vertical scale indicates the percentage identity, ranging from $50 \%$ to $100 \%$. Divergent hotspot refers to the places with more variable sites compared to other regions. 


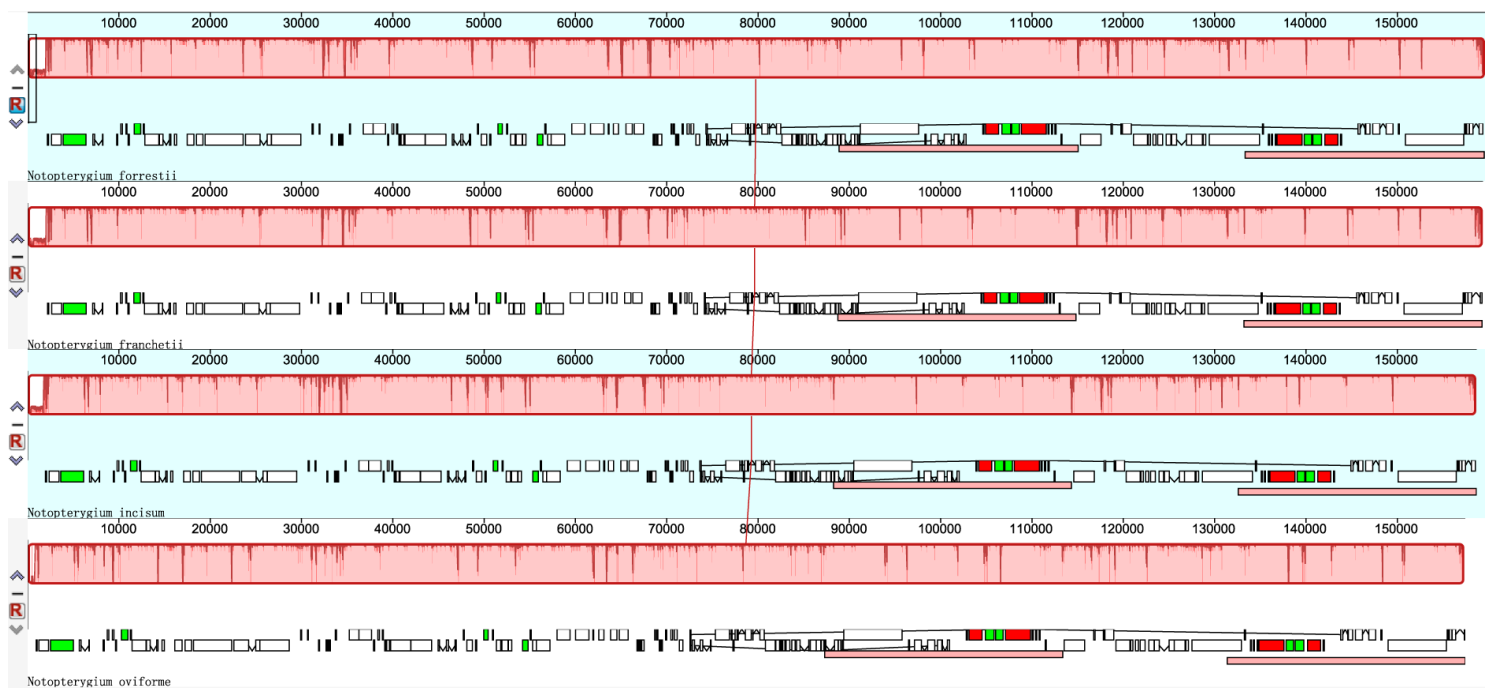

Figure 3. MAUVE alignment of four Notopterygium species chloroplast genomes. The N. forrestii genome is shown at top as the reference genome. Within each of the alignments, local collinear blocks are represented by blocks of the same color connected by lines.

Table 3. Base compositions of chloroplast genomes of four Notopterygium species.

\begin{tabular}{|c|c|c|c|c|c|}
\hline Region & & N. incisum & N. oviforme & N. franchetii & N. forrestii \\
\hline \multirow{5}{*}{ LSC (\%) } & $\mathrm{A}$ & 31.5 & 31.4 & 31.5 & 31.6 \\
\hline & $\mathrm{T}$ & 32.7 & 32.6 & 32.7 & 32.6 \\
\hline & $\mathrm{C}$ & 18.4 & 18.3 & 18.4 & 18.4 \\
\hline & G & 17.4 & 17.7 & 17.4 & 17.4 \\
\hline & GC & 35.8 & 36.0 & 35.8 & 35.8 \\
\hline \multirow{5}{*}{ SSC (\%) } & $\mathrm{A}$ & 34.6 & 34.4 & 34.6 & 34.6 \\
\hline & $\mathrm{T}$ & 33.8 & 33.8 & 33.8 & 33.8 \\
\hline & $\mathrm{C}$ & 16.5 & 16.5 & 16.5 & 16.4 \\
\hline & $\mathrm{G}$ & 15.1 & 15.2 & 15.1 & 15.1 \\
\hline & GC & 31.6 & 31.7 & 31.6 & 31.6 \\
\hline \multirow{5}{*}{ IRa (\%) } & $\mathrm{A}$ & 28.3 & 28.2 & 28.3 & 28.3 \\
\hline & $\mathrm{T}$ & 28.7 & 28.5 & 28.7 & 28.7 \\
\hline & $\mathrm{C}$ & 22.1 & 22.1 & 22.2 & 22.2 \\
\hline & $\mathrm{G}$ & 20.8 & 21.2 & 20.8 & 20.8 \\
\hline & GC & 42.9 & 43.3 & 43.0 & 43.0 \\
\hline \multirow{5}{*}{$\mathrm{IRb}(\%)$} & A & 28.7 & 28.6 & 28.7 & 28.6 \\
\hline & $\mathrm{T}$ & 28.3 & 28.2 & 28.3 & 28.4 \\
\hline & $\mathrm{C}$ & 20.8 & 21.0 & 20.8 & 20.8 \\
\hline & $\mathrm{G}$ & 22.1 & 22.2 & 22.2 & 22.2 \\
\hline & GC & 42.9 & 43.2 & 43.0 & 43.0 \\
\hline \multirow{5}{*}{$\begin{array}{c}\text { overall } \\
\text { length (\%) }\end{array}$} & $\mathrm{A}$ & 30.9 & 30.8 & 30.9 & 30.9 \\
\hline & $\mathrm{T}$ & 31.4 & 31.3 & 31.4 & 31.4 \\
\hline & $\mathrm{C}$ & 19.2 & 19.2 & 19.2 & 19.2 \\
\hline & $\mathrm{G}$ & 18.5 & 18.8 & 18.5 & 18.5 \\
\hline & GC & 37.7 & 37.9 & 37.7 & 37.7 \\
\hline
\end{tabular}

Taking the example of $N$. incisum, protein-coding, rRNA, and tRNA genes were encoded by $49.50 \%, 5.70 \%$, and $1.80 \%$ of the whole cp genome, respectively (Table S4). The 30 unique tRNA genes encoded all of the 20 amino acids (aa) essential for protein biosynthesis. The length of protein-coding sequences was 78,531 bp and comprised 79 unique protein genes. These protein-coding sequences coded for 26,177 codons (Table S4). Interestingly, leucine $(10.50 \%)$ and cysteine $(1.10 \%)$ were the 
maximum and minimum commonly code aa, respectively (Table S5, Figure 4). Among these codons, the maximum codon usage was TTA (852) encoding leucine, and minimum codon usage was TGC (68) encoding cysteine, respectively (Table S6).

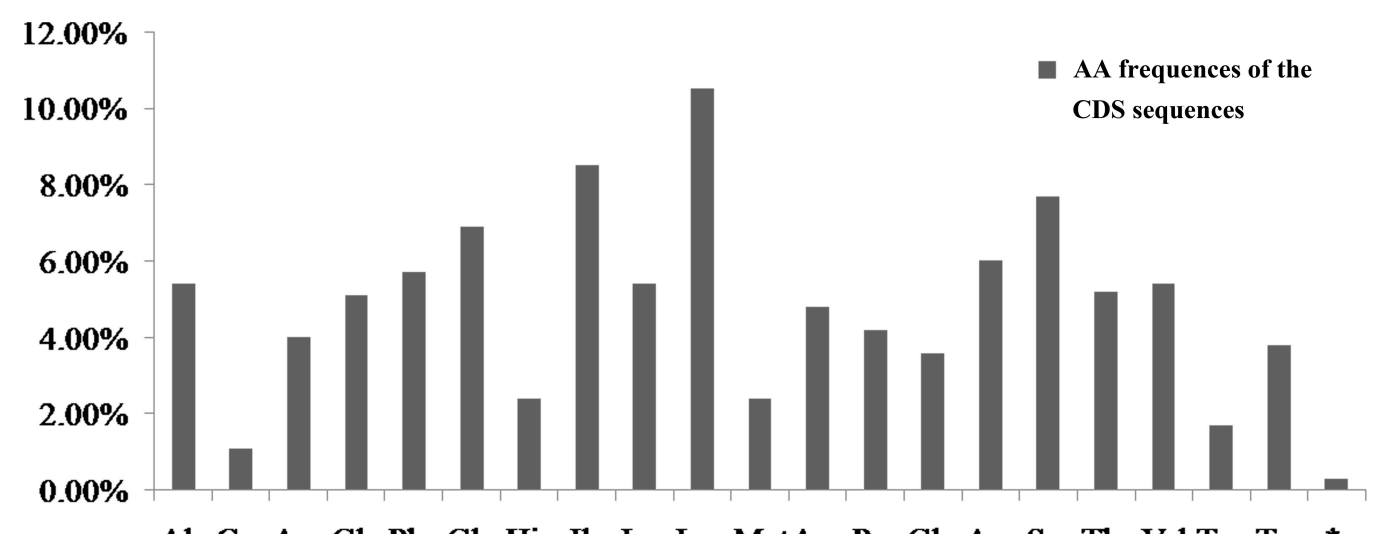

Figure 4. Amino acid frequencies of the N. incisum protein-coding sequences. ${ }^{*}$ Termination codon.

\subsection{Repetitive Sequences}

The larger repeats constituted by IRa and IRb resulted in plastid genomes which contained lots of repeated sequences. In the present study, we counted four kinds of repetitions: dispersed, tandem, palindromic and tRNA or gene-similar repeats. All of the repeats were manually verified and redundant parts were removed. Among these types, the numbers and distributions of the repeats in the four cp DNA were similar and conserved (Figure 5). Dispersed unit was the most repeated type (241), the next was palindromic repeat (180), the tandem type was 152, the least one was tRNA or gene-similar repeats (15) (Figure 5). The lengths of the repeat units were mainly concentrated on 2 to $32 \mathrm{bp}$. Most of them were distributed in intergenic or intron regions, and only a minority were located in gene regions, e.g., ycf3, rps18, ycf2, rpoC1, psbT, petB, ycf1, rps19 (Table S7). N. oviforme had the largest dispersed (100), palindromic (50), and tandem (40) repeats in all four species. N. franchetii and N. forrestii had similar palindromic and tandem repeats. Meanwhile, the repeats among four Notopterygium species had few differences; the length of repeat was mainly located in 9-24 bp region, but $N$. oviforme had larger change compared with other three species (Figure 5). In four types, dispersed, accounting for $41.2 \%$ of total repeats, were the most common (Figure 5). The largest dispersed was $463 \mathrm{bp}$ in the interval of 1-8 bp repeat length and the least repeat was one bp in N. oviforme (Figure 5).

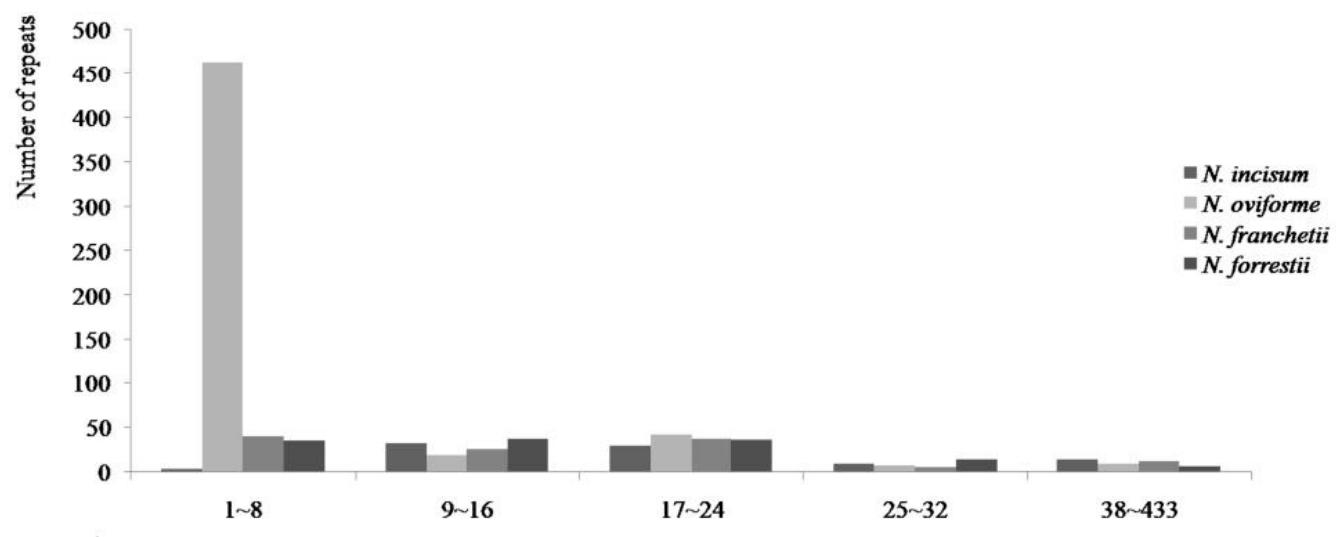

Figure 5. Cont. 


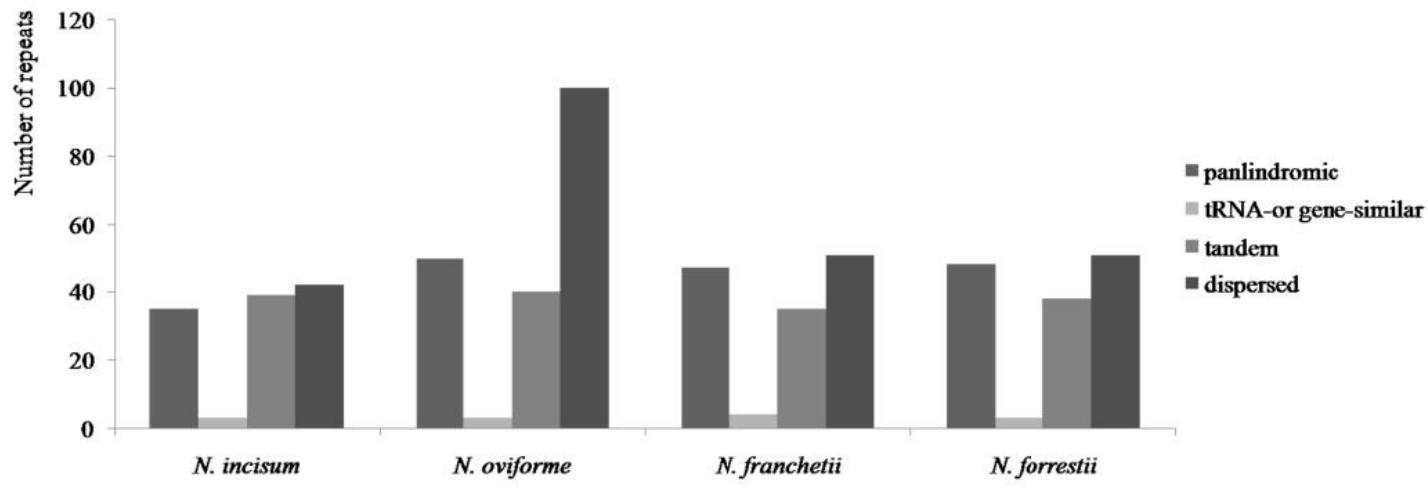

B

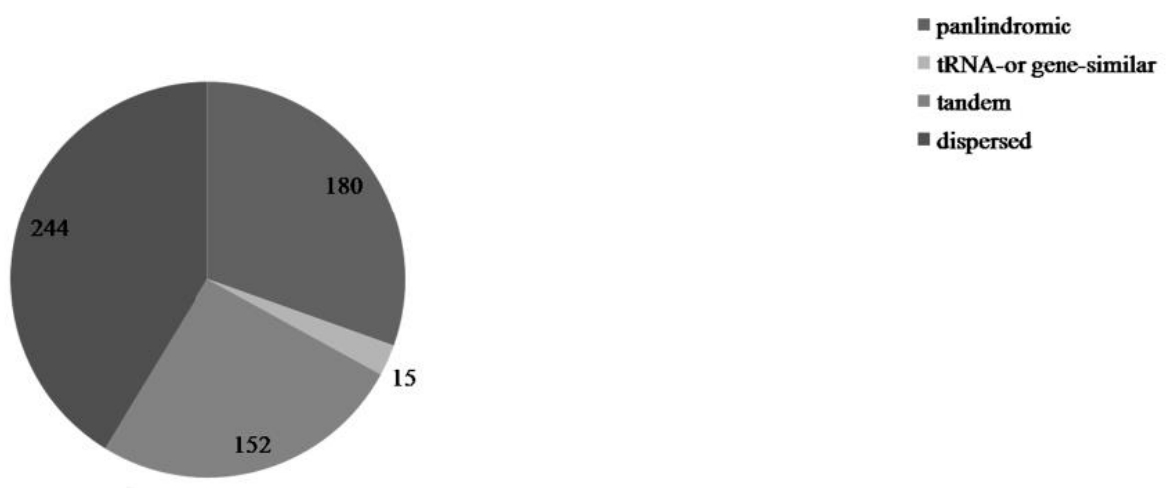

C

Figure 5. Repeat analyses. (A) Histogram showing the number of repeats in the four Notopterygium chloroplast genomes. (B) Compositions of the repeats from four Notopterygium species. (C) Pie chart showing the numbers of four repeat types.

\subsection{Sequence Divergence among Notopterygium Species}

mVISTA was used to perform a sequence identity analysis, with N. incisum as a reference (Figure 2). The results indicated that the high sequence similarities across four cp genomes, which suggested that there were few variations, the plant evolution of Notopterygium was relatively conservative. In addition, as we expected, noncoding regions exhibited a higher level of divergence than coding regions in the complete cp genome. In noncoding regions, the percentage of variations ranged from 0 to $33.40 \%$, with an average of $6.39 \%$, which was 4.6 -fold higher than that in the coding regions ( $1.37 \%$ on average) (Figure 6). The mean percentages of variations were $6.42 \%, 4 \%$ and $8 \%$ in the LSC, IRs and SSC regions in noncoding regions, respectively. There were no significant differences among these regions $(1.57 \%$, $0.35 \%$ and $0.73 \%$ for LSC, IRs and SSC regions) in the coding regions (Table S8) identified for the four species. In addition, we found that the IR regions had fewer mutations and were highly conserved in the sampled four Notopterygium species. More remarkably, some genes that were located in LSC region ( $r p s 16, p s a I, p s b T, p s b H, p e t B, r p o A$ and $r p s 11$ ) exhibited higher variability (average value $>3 \%$ ) than other genes. Particularly, pasI (10.20\%) gene had a highly variable (Table S9) in the genus Notopterygium. 

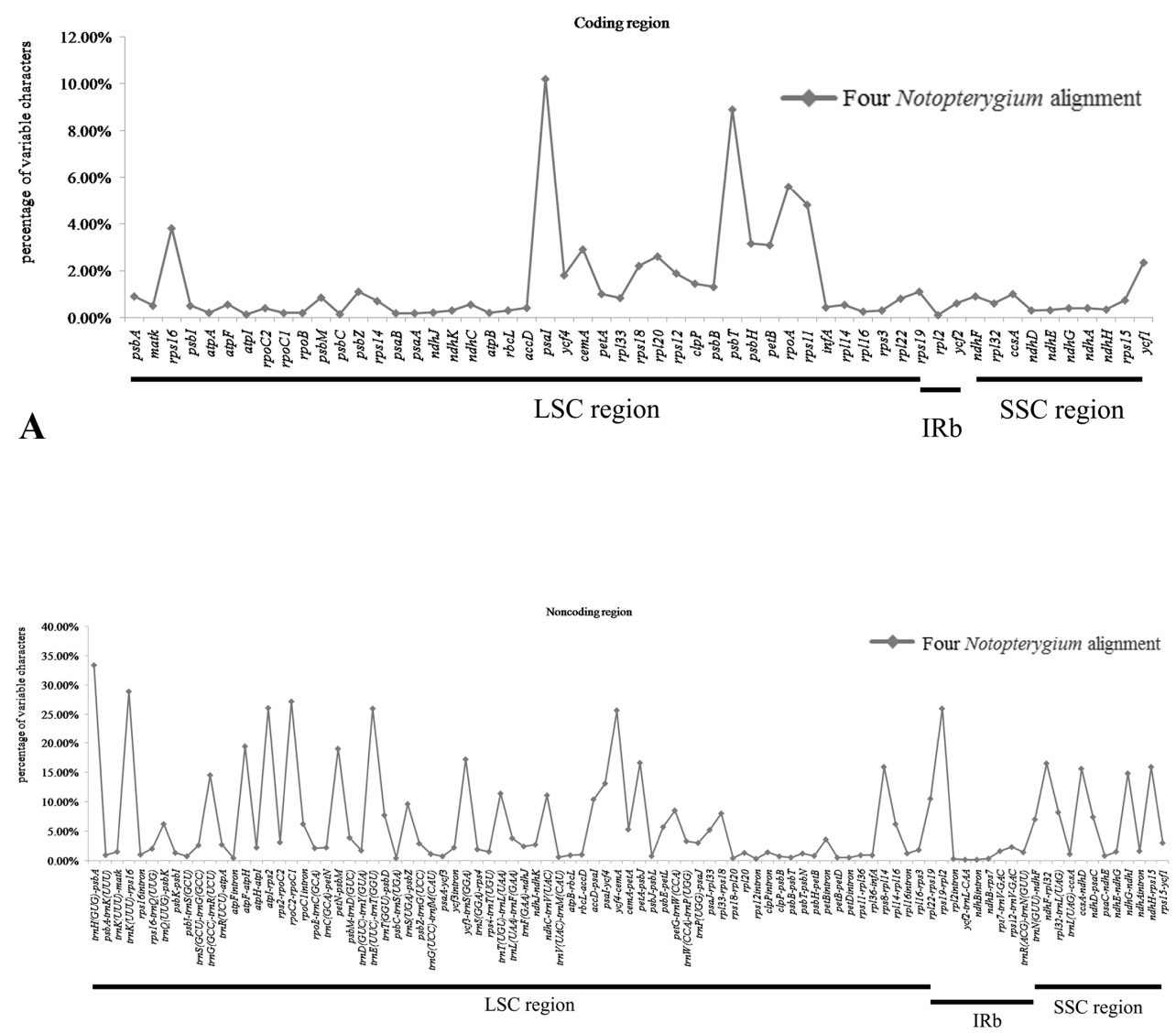

B

Figure 6. Percentages of variable characters in homologous regions among chloroplast genomes of four Notopterygium species. (A) Coding region. (B) Noncoding region. The homologous regions are oriented according to their locations in the chloroplast genome.

\subsection{Evolutionary Rates of Notopterygium}

To estimate selection pressures of chloroplast genes, $\mathrm{dN}, \mathrm{dS}$ and $\omega$ of 79 protein-coding genes were computed and compared in four Notopterygium species (Figure 7). Only 24 protein-coding gene have $\omega$ values from 86 pairwise comparison numerations. The $\omega$ value of the remaining comparisons could not be calculated because of $\mathrm{dN}$ or $\mathrm{dS}=0$. When the $\omega$ value was within $0.8-1$, it contained $a c c D, n d h D, r p o C 1$ genes. The $\omega$ value of three genes ( $p s a I, p s b I$ and $r p o A$ ) significantly exceeded 1.0 (Figure 7) in four species. In a pair of N. oviforme and N. incisum species, the $\omega$ value of $p s b I$ and $r p o A$ genes were just be seen to exceed 1 . Meanwhile, the $p s b I$ and $r p o C 1$ genes exhibited the maximum $\mathrm{dN}$ (0.1882) and the minimum dS (0.0011) respectively (Table S10). The $p s b$ and $p s a$ genes were positively selected to a greater extent than the other genes (Figure 7). A comparison among individual genes in each functional group showed that substitution rates fluctuated widely among the 24 coding genes, with $\mathrm{dN}$ values ranging from 0.0006 to 0.1882 and $\mathrm{dS}$ values ranging from 0.0011 to 0.1495 (Table S10), respectively. Most genes exhibited $\omega$ less than 0.5 , indicating the efficiency of purifying selection. Three genes ( $p s a I, p s b I$ and $r p o A$ ) were functionally essential in photosynthesis and self-replication (Table 2), that $\omega$ values were significantly greater than unity $(1.3043,1.9149$ and 1.0121) in the four sampled Notopterygium species. It is suggested these genes were possibly under positive selection in these endangered species. 


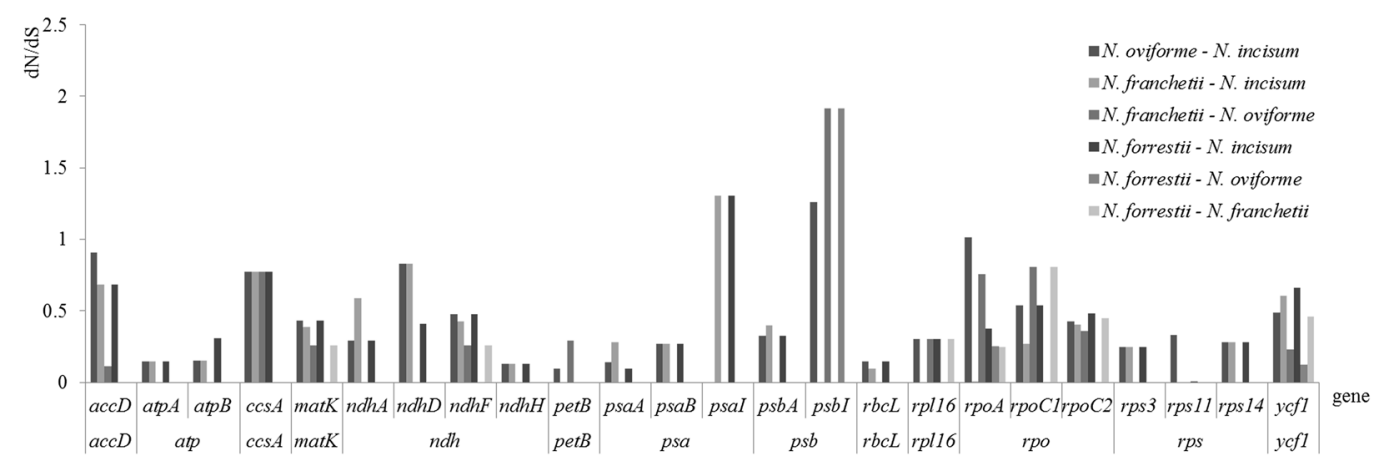

Figure 7. Nonsynonymous substitution (dN), Synonymous substitution $(\mathrm{dS})$, and $\mathrm{dN} / \mathrm{dS}(\omega)$ values for individual genes or gene groups.

\subsection{Phylogenomic Relationship of Notopterygium Species}

Six data partitions (whole cp genomes; all data excluding the IR region; the LSC region; the SSC region; the protein-coding sequences and the IR region) of 19 Apiaceae and Araliaceae cp genomes were used to construct the phylogenetic relationships. The maximum likelihood (ML) analyses yielded similar topology trees in all datasets (Figure 8). The two genetic clusters were recovered, one was Apiaceae clade, another clade was corresponded to the Araliaceae species. Four Notopterygium species were gathered within a clade with strong bootstrap support in the cp DNA tree. In addition, the monophyletic clade of the four Notopterygium species was also identified by nuclear ITS datasets with strong posterior support. However, there are some inconsistent phylogenetic relationships among the four Notopterygium species for two types of datasets. In the cp DNA tree, N. oviforme and N. forrestii had the closer relationship, while N. incisum and N. franchetii were polyphyletic. In the ITS tree, the ITS haplotypes of each Notopterygium species clustered into one individual species that corresponded to themselves, respectively (Figure 9). In addition, the ITS haplotypes of N. oviforme and N. franchetii formed a large clade with moderate bootstrap.

\section{Discussion}

\subsection{The Relationship of AT Content and Codon Usage of the Four Notopterygium Species}

Many complete cp genomes of Apiaceae species were reported in NCBI, but no published cp genomes were documented for the endangered Notopterygium species. In the present study, we firstly obtained whole plastid genomes of four Notopterygium species, which will generally contribute to covering the gap in the knowledge of plastid genome evolution in Notopterygium. In terms of GC content, the cp genomes of $N$. incisum, N. franchetii and N. forrestii had the same GC content $(37.70 \%)$, but $N$. oviforme had a subtle difference (37.90\%) compared with others. The GC contents of the LSC and SSC regions (35.8\% and 31.6\%) were lower than that in the IR regions (43\%). The high GC percentages in the IR regions was possibly due to the presence of four rRNA sequences in these regions, e.g., $r r n 16$, $r r n 23, r r n 4.5, r r n 5$. These results are consistent with the previously reported high GC percentage in the IR regions in the many complete cp genomes of angiosperms [53]. 


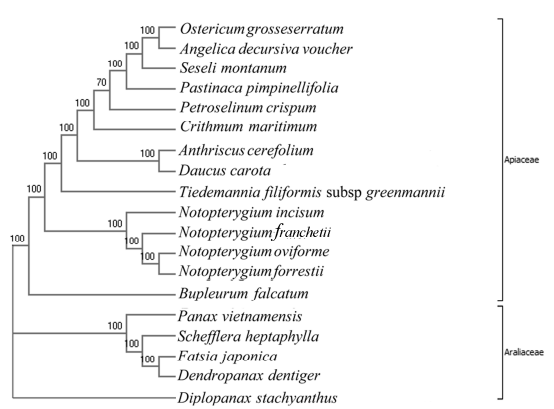

A

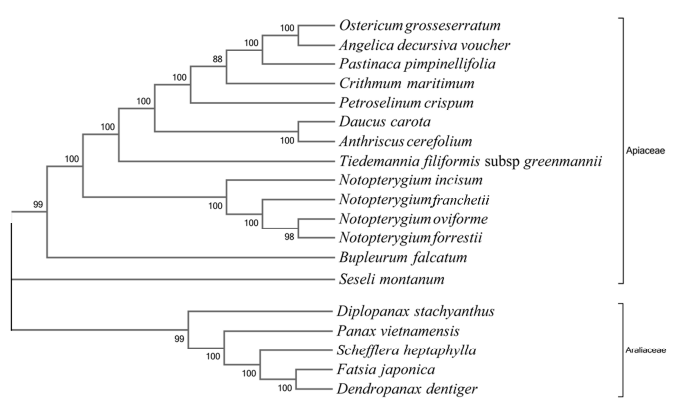

C

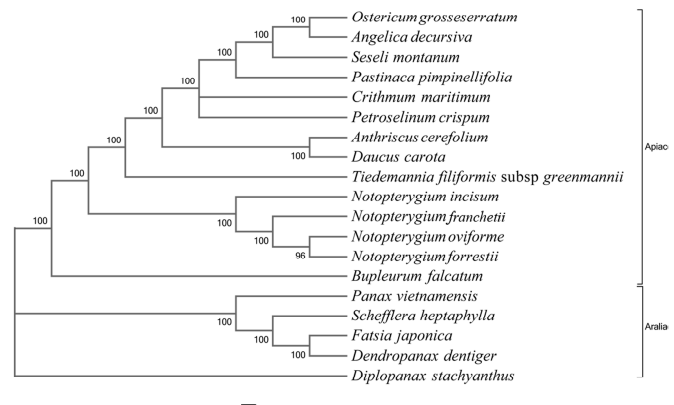

E

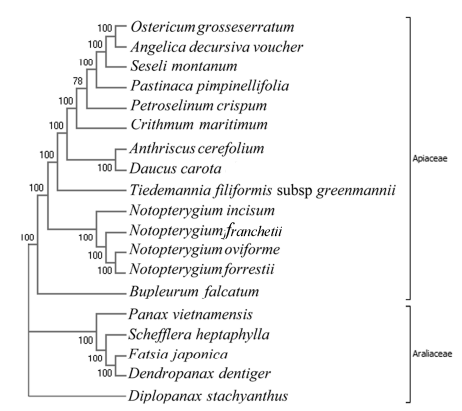

B

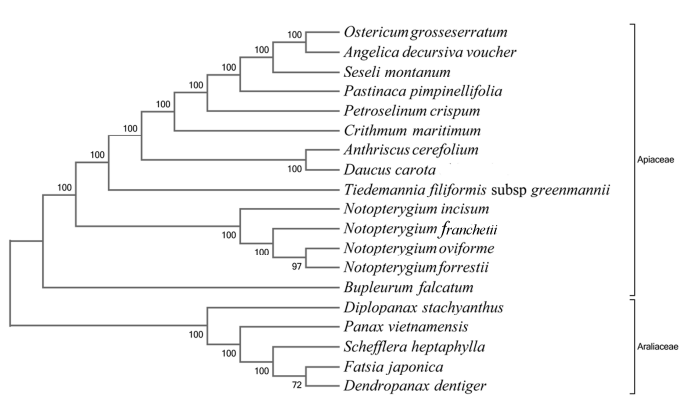

D

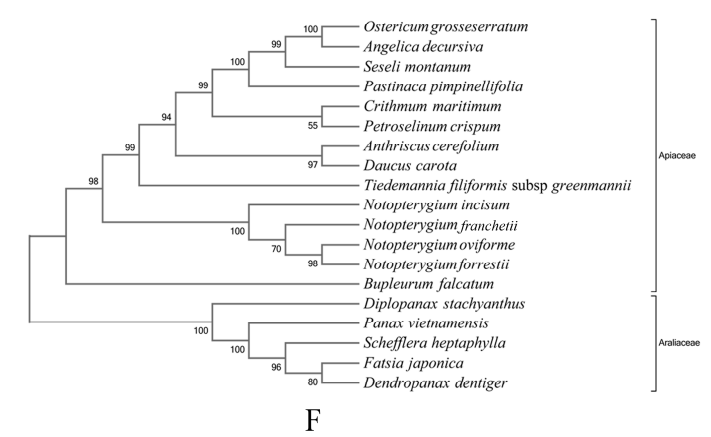

Figure 8. Cladogram of 19 Apiaceae and Araliaceae species using Maximum likelihood (ML) analysis based on (A) whole chloroplast genomes, (B) all data excluding an IR region, (C) the LSC region, (D) the SSC region, (E) the protein-coding sequences and $(\mathbf{F})$ the IR region.

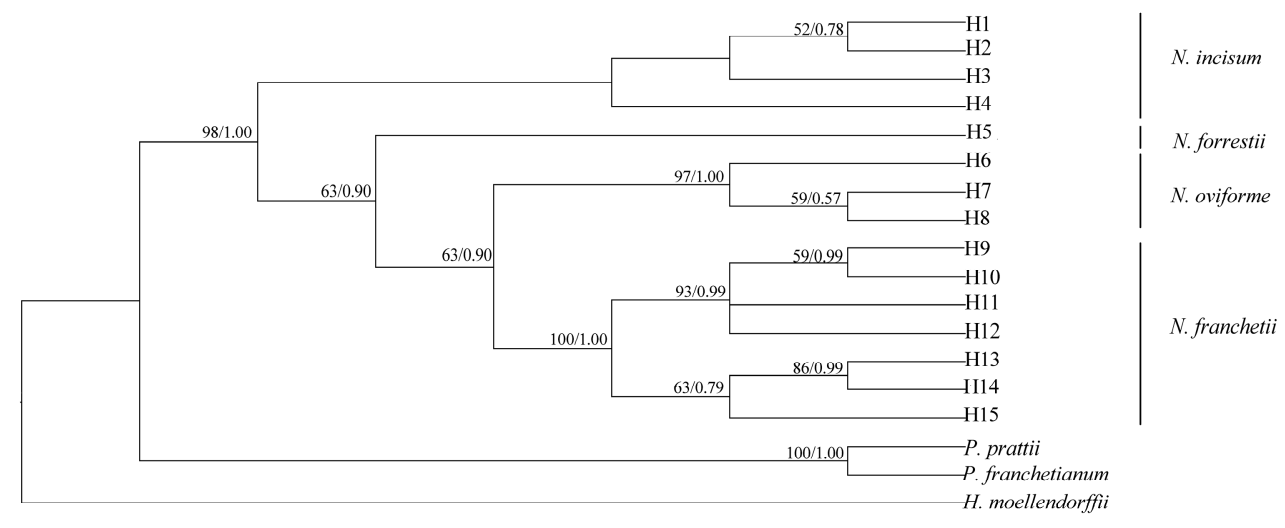

Figure 9. Phylogenetic relationship of ITS haplotypes of four Notopterygium species inferred from ML and Bayesian inference (BI) analyses. Numbers above the lines on the left indicate the ML bootstrap of clade $>50 \%$, numbers above the lines on the right indicate the Bayesian posterior probabilities. 
Meanwhile, the AT contents of unique 113 predicted genes were very high in the four Notopterygium species (Table S11). Of these genes, 79 protein-coding, 30 tRNA and four rRNA genes were included (Figure 1, Tables 1 and 2). The 30 unique tRNA genes included all of the 20 aa required for protein biosynthesis, that also have determined the codon usage [54]. Generally speaking, composition bias was discovered as a predominant factor influencing codon bias in cp genome of plants. The composition bias of a high AT content was more matches in the noncoding regions in plants [55]. In this study, we identified the 30 tRNA genes that all had a high AT content (Table S11). Therefore, the composition bias was very similar among these genomes. In fact, two factors, with different relative importance, contributed to codon bias in different plant species [56,57]. The first reason was that the genome composition bias generated a bias in degenerated positions of coding sequences [58]. The second one was the choice of specific codons in the coding regions, most likely to increase the translation efficiency $[54,56,59]$. The evidence for this type of selection was primarily supported by Escherichia coli where codon usage was adapted to the number of tRNA in the cell [54], and the degree of codon bias varied in these genes, associated with expression level of some particular genes [56,57].

\subsection{Sequence Divergence}

In our sequenced genomes, divergent regions were often found associated with many repeats. We identified the similar high frequencies of repeats in these four $\mathrm{cp}$ genomes. The repeats in these species usually were located in the same genes and/or intergenic regions (e.g., ycf2, ycf3). Generally speaking, the elements of repeats were related to the rearrangement of the plastome, generating highly divergent regions via illegitimate, recombination and slipped-strand mispairing [60-62]. In addition, the gene order of grass cp genomes was distinct from that of standard angiosperm ones due to three typical inversions, inversion 1 ( $28 \mathrm{~kb}$ in length), inversion $2(\approx 6 \mathrm{~kb})$ and inversion 3 (individual trnT gene) [63]. A recent study of plastome from basal asterids indicated the conservation of the repeat patterns in the coding region, whereas the repeat evolution in the noncoding region was lineage-specific [64]. In the present study, we identified some repeats that were associated with two tRNA (e.g., trnI-GAU) copies, or gene duplication (e.g., ycf2/ycf3). These repeats might be due to similarity of gene functions and thus we classified them into another type tRNA or gene similarity [52].

Meanwhile, the genetic divergence was very low among the four Notopterygium cp genomes. After the four cp genomes were aligned, we plotted sequence identity using mVISTA with N. incisum as a reference (Figure 2). The results showed high similarities among cp genomes, with only a few sequence identities falling below $90 \%$, suggesting that the Notopterygium $\mathrm{cp}$ genomes were rather conserved. A small divergence was found in LSC, with less mutations in IRs. In addition, one divergent hotspot region associated with a tRNA cluster in the noncoding regions containing the $\operatorname{trnC}-G C A$, trnD-GUC, trnY-GUA, trnT-GGU, and trnE-UUC was identified in the four Notopterygium species. These hotspot regions identified could be used in phylogenetic analyses, or serve as potential DNA molecular barcodes $[52,65,66]$.

\subsection{Phylogenomic Relationships among the Four Notopterygium Species}

$\mathrm{Cp}$ genomes of plant species provide rich sources of phylogenetic information. Numerous phylogenetic studies based on the cp DNA sequences have been carried out during the past two decades, greatly enhancing our understanding of the evolutionary relationships among angiosperms $[9,67,68]$. Plastid genome also has been proven to be effective in resolving difficult phylogenetic relationships among closely related species $[69,70]$. Complete sequencing and mutual comparative analyses demonstrated that the four Notopterygium cp genomes bore a high level of conservation in terms of architecture and linear sequence order. As shown in the phylogenetic tree (Figure 8), two major genetic clusters were identified, one was Apiaceae, including the sampled four Notopterygium species. Another one was Araliaceae clade, including five cp genomes. The monophyletic clade of the four Notopterygium species was identified with strong bootstrap support. 
In addition, $N$. oviforme and $N$. forrestii had the closely relationship in the chloroplast phylogenetic tree, however N. oviforme and N. franchetii had the closely relationship in the nrDNA ITS tree. So, there are some differences in phylogenetic relationships within the genus Notopterygium. We analyze the reasons for this incongruence between nuclear and chloroplast DNA phylogenies in the following. First, the nuclear ITS region is shorter and has a higher mutation rate than the chloroplast DNA (ITS: $8.85 \%$, 54 variable sites out of $610 \mathrm{bp}$; complete chloroplast genome: $1.37 \%$, coding region, $6.39 \%$, noncoding region) (Tables S8 and S12). Secondly, the nuclear ITS region is biparentally inherited and dispersed by both pollen and seeds, while the chloroplast DNA fragments are maternally inherited and dispersed only by seeds [71]. Thus, the ITS region has higher intraspecific gene flow and higher efficiency of species identification than the chloroplast regions [72]. Thirdly, we did not rule out that the incongruence between nuclear and $\mathrm{cp}$ DNA relationships may be due to the difference of sampling strategies between two types of sequences. In this study, we sampled multiple individuals for ITS analyses, and only one individual for each cp DNA genome. In addition, the incomplete lineage sorting, convergence evolution or hybridization and gene infiltration among species [73-77] may have caused the incongruence between different inherited background markers. In the other words, these results together suggested that the Notopterygium species may have experienced a complex evolutionary history and speciation process. The present study also illustrated that the comparative analyses between $\mathrm{cp}$ DNA and ITS regions can help understand the comprehensive and deeply evolutionary process and phylogenetic relationships.

\subsection{Evolutionary Rates among Notopterygium Species}

A previous study showed that the alpine plants have various adaptive strategies under unpredictable environmental conditions [78]. Faster evolution of the cold-related genes had clearly been demonstrated in the evolution of alpine species [79]. For instance, the whole transcriptome analysis of Cardamine kokaiensis suggested that the adaptive evolution of this species to the extreme environments, particularly the chilling temperatures $[78,80]$. Generally speaking, cold temperatures and high irradiation were found to be not beneficial to efficient photosynthesis of plant species, and therefore, a set of photosynthetic protection strategies were desired for survival and reproduction in high altitude plants [81-85]. The Notopterygium species are mainly distributed in the alpine mountains of the Qinghai-Tibetan Plateau and adjacent regions [3]. So, these species might also have some mechanisms to adapt to cold alpine conditions. As shown above, the $\mathrm{dN}$ and $\mathrm{dS}$ rates might indicate the constraints of natural selection on organisms, estimation of these mutations $(\omega)$ played a pivotal role in understanding the dynamics of molecular evolution of plant species [86]. In this study, we identified the highest $\omega$ value was 1.9149 for $p s b I$ gene, far exceeding one among the four Notopterygium species. The other two genes were psaI (1.3043) and rpoA (1.0121), whose $\omega$ values both exceeded one (Table S10). Noticeably, $r p o A$ and $p s a I$ genes had also been found to have significant variance in coding regions (Table S9). These genes might have suffered positive selection in these endangered Notopterygium species. For the pair of $N$. oviforme and $N$. incisum, the $\omega$ value of the $\operatorname{acc} D, \operatorname{ccs} A$ and $n d h D$ genes were approximately one. The estimations of substitution rate of these genes indicated that $N$. incisum and N. oviforme had evolved at variable rates, and patterns of substitution were differentiated in functional categories and lineages. Based on our knowledge of the genomic information, these variable rates were related to a number of factors, such as functional constraints, relaxed or positive selection, and gene expression level [87].

Similarly, psaI and psbI, encoding photosystems subunits (Table 2), played an important role in the life history of plant. In addition, the $r p o A$ gene encoding DNA-dependent RNA polymerase (Table 2) and the $\alpha$ subunit of RNA polymerase (RNAP) in plants [87]. The $r p o A$ gene was also observed in the $\mathrm{cp}$ of live moss protonemata cells. These results indicated that the strong selective pressure may have acted against broad variations in these functional genes [88]. In this study, we identified that the psbI gene has great differences between the four Notopterygium species. Compared with N. incisum, psbI gene contracted in size and shifted left in location in the N. oviforme cp genome. Extensively, the 
mutation rates were more variable in the genes that contained $a c c D, \operatorname{cs} A$, matK, ndhD, psaI, psbI, and $y c f 1$ genes, as evidenced by the higher $\omega$ value (Figure 7). Here the other two genes, $y c f 1$ and $a c c D$ genes had been reported in other plant lineages and had also experienced fast evolution. For instance, the $y c f 1$ gene had been classified as the most divergent one in plastome of vascular plants [89]. The $a c c D$ had been proven to be an essential gene in the cp genome evolution [90]. More significantly, there was direct evidence that the $a c c D$ gene could affect plant fitness and leaf longevity [91]. Consequently, these results indicated that these genes might be involved in the adaptation to the specific ecological environment during the evolution of Notopterygium species.

Supplementary Materials: The following are available online at www.mdpi.com/2073-4425/8/4/124/s1. Table S1: Sample information of cp DNA and ITS datasets of four Notopterygium species, Table S2: Ten complete chloroplast genomes of Apiaceae and five complete chloroplast genomes of Araliaceae species from GenBank, Table S3: Assembled reads of four Notopterygium species, Table S4: The encode frequencies of protein-coding, tRNA and rRNA sequences of Notopterygium incisum, Table S5: Amino acid frequencies of chloroplast protein-coding sequences of Notopterygium, Table S6: Codon and the frequencies of amino acid in Notopterygium incisum, Table S7: Repeat sequences in Notopterygium chloroplast genomes (see details in the excel file entitled Table S7), Table S8: The variation rates in Notopterygium chloroplast genomes, Table S9: Percentages of variable characters in coding and noncoding regions, Table S10: Nonsynonymous substitution (dN), Synonymous substitution (dS), and dN/dS( $\omega$ ) values for individual genes or gene groups (see details in the excel file entitled Table S10), Table S11: The AT contents of gene in coding and noncoding regions, Table S12: The variable sites of ITS sequence of Notopterygium species (see details in the excel file entitled Table S12).

Acknowledgments: We are very grateful to Aureliano Bombarely and two anonymous reviewers for their helpful suggestions and comments. This work was supported by the National Natural Science Foundation of China (31470400), the National Key R \& D Program for Crop Breeding (2016YFD0100300) and the Program for Changjiang Scholars and Innovative Research Team in University (PCSIRT, No. IRT_15R55).

Author Contributions: Z.-H.L. designed the research. J.Y. and C.N. performed the experiments. J.Y., Z.-H.L., M.Y. and X.-F.M. contributed materials/analysis tools. J.Y. and Z.-H.L. wrote the paper. Z.-H.L., J.Y. and X.-F.M. revised the paper. All authors approved the final manuscript.

Conflicts of Interest: The authors declare no conflict of interest. The funding sponsors had no role in the design of the study; in the collection, analyses, or interpretation of data; in the writing of the manuscript, and in the decision to publish the results.

\section{References}

1. Wu, Z.Y.; Raven, P.H. Flora of China. Volume 14. Apiaceae through Ericaceae; Science Press: Beijing, China, 2005.

2. Xu, H.B.; Sun, X.B. Study on the pharmacological effects of volatile oil of Notopterygium incisum. Chin. Tradit. Herb. Drugs 1991, 22, 28-30.

3. Zhou, Y.; Jiang, S.Y.; Ma, X.J.; Sun, H.; Pu, F.D.; Wu, R. Resource crisis and protective measures on rhizoma et radix Notopterygii. Chin. Tradit. Herb. Drugs 2003, 34, 12-14.

4. Wang, Y.P.; Pu, F.D.; Wang, P.L.; He, X.J. Studies on the systematics of the Chinese endemic genus Notopterygium. Acta Bot. Yunnanica 1995, 18, 424-430.

5. Pu, F.D.; Wang, P.L.; Zheng, Z.H.; Wang, Y.P. A reclassification of Notopterygium Boissieu (Umbelliferae). Acta Phytotaxon. Sin. 1999, 38, 430-436.

6. Jiang, S.Y.; Sun, H.; Huang, X.J.; Zhou, Y.; Ma, X.J.; Yang, Z.R. Environmental pedology of Notopterygium incisum and N. forbesii. Chin. Tradit. Herb. Drugs 2005, 36, 918-921.

7. Yang, X.W.; Zhang, P.; Tao, H.Y.; Jiang, S.Y.; Zhou, Y. GC-MS analysis of essential oil constituents from rhizome and root of Notopterygium forbesii. J. Chin. Pharm. Sci. 2006, 15, 200-205.

8. Wang, S. China Species Red List; Higher Education Press: Beijing, China, 2004.

9. Jansen, R.K.; Cai, Z.Q.; Raubeson, L.A.; Daniell, H.; de Pamphilis, C.W.; Leebens-Mack, J.; Müller, K.F.; Guisinger-Bellian, M.; Haberle, C.R.; Hansen, A.K.; et al. Analysis of 81 genes from 64 plastid genomes resolves relationships in angiosperms and identifies genome-scale evolutionary patterns. Proc. Natl. Acad. Sci. USA 2007, 104, 19369-19374. [CrossRef] [PubMed]

10. Moore, M.J.; Soltis, P.S.; Bell, C.D.; Burleigh, J.G.; Soltis, D.E. Phylogenetic analysis of 83 plastid genes further resolves the early diversification of eudicots. Proc. Natl. Acad. Sci. USA 2010, 107, 4623-4628. [CrossRef] [PubMed] 
11. Shaw, J.; Shafer, H.L.; Leonard, O.R.; Kovach, M.J.; Schorr, M.; Morris, A.B. Chloroplast DNA sequence utility for the lowest phylogenetic and phylogeographic inferences in angiosperms: The tortoise and the hare IV. Am. J. Bot. 2014, 101, 1987-2004. [CrossRef] [PubMed]

12. Sugiura, M. The chloroplast genome. Plant Mol. Biol. 1992, 19, 149-168. [CrossRef] [PubMed]

13. Sugiura, M. The chloroplast genome. Essays Biochem. 1994, 30, 49-57.

14. Tangphatsornruang, S.; Sangsrakru, D.; Chanprasert, J.; Uthaipaisanwong, P.; Yoocha, T.; Jomchai, N.; Tragoonrung, S. The chloroplast genome sequence of mungbean (Vigna radiata) determined by high-throughput pyrosequencing: Structural organization and phylogenetic relationships. DNA Res. 2009, 17, 11-22. [CrossRef] [PubMed]

15. Jansen, R.K.; Palmer, J.D. A chloroplast DNA inversion marks an ancient evolutionary split in the sunflower family (Asteraceae). Proc. Natl. Acad. Sci. USA 1987, 84, 5818-5822. [CrossRef] [PubMed]

16. Palmer, J.D. Plastid chromosomes: Structure and evolution. In Molecular Biology of Plastids; Bogorad, L., Vasil, I.K., Eds.; Academic Press: San Diego, CA, USA, 1991; pp. 5-53.

17. Wicke, S.; Schneeweiss, G.M.; Müller, K.F.; Quandt, D. The evolution of the plastid chromosome in land plants: Gene content, gene order, gene function. Plant Mol. Biol. 2011, 76, 273-297. [CrossRef] [PubMed]

18. Zhu, A.; Guo, W.; Gupta, S.; Fan, W.; Mower, J.P. Evolutionary dynamics of the plastid inverted repeat: the effects of expansion, contraction, and loss on substitution rates. New Phytol. 2016, 209, 1747-1756. [CrossRef] [PubMed]

19. Parks, M.; Cronn, R.; Liston, A. Increasing phylogenetic resolution at low taxonomic levels using massively parallel sequencing of chloroplast genomes. BMC Biol. 2009, 7, 84. [CrossRef] [PubMed]

20. Burke, S.V.; Grennan, C.P.; Duvall, M.R. Plastome sequences of two new world bamboos-Arundinaria gigantea and Cryptochloa strictiflora (Poaceae)-extend phylogenomic understanding of Bambusoideae. Am. J. Bot. 2012, 99, 1951-1961. [CrossRef] [PubMed]

21. Huang, H.; Shi, C.; Liu, Y.; Mao, S.Y.; Gao, L.Z. Thirteen Camellia chloroplast genome sequences determined by high-throughput sequencing: Genome structure and phylogenetic relationships. BMC Evol. Biol. 2014, 14, 1-17. [CrossRef] [PubMed]

22. Walker, J.F.; Zanis, M.J.; Emery, N.C. Comparative analysis of complete chloroplast genome sequence and inversion variation in Lasthenia burkei (Madieae, Asteraceae). Am. J. Bot. 2014, 101, 722-729. [CrossRef] [PubMed]

23. Ané, C.; Burleigh, J.G.; McMahon, M.M.; Sanderson, M.J. Covarion structure in plastid genome evolution: A new statistical test. Mol. Biol. Evol. 2005, 22, 914-924. [CrossRef] [PubMed]

24. Lin, C.P.; Huang, J.P.; Wu, C.S.; Hsu, C.Y.; Chaw, S.M. Comparative chloroplast genomics reveals the evolution of Pinaceae genera and subfamilies. Genome Bio. Evol. 2010, 2, 504-517. [CrossRef] [PubMed]

25. Barrett, C.F.; Davis, J.I.; Leebens-Mack, J.; Conran, J.G.; Stevenson, D.W. Plastid genomes and deep relationships among the commelinid monocot angiosperms. Cladistics 2013, 29, 65-87. [CrossRef]

26. Raman, G.; Choi, K.S.; Park, S. Phylogenetic relationships of the fern Cyrtomium falcatum (Dryopteridaceae) from Dokdo island based on chloroplast genome sequencing. Genes 2016, 7, 115. [CrossRef] [PubMed]

27. Alkan, C.; Sajjadian, S.; Eichler, E.E. Limitations of next-generation genome sequence assembly. Nat. Methods 2011, 8, 61-65. [CrossRef] [PubMed]

28. Huang, L.K.; Yan, H.D.; Zhao, X.X.; Zhang, X.Q.; Wang, J.; Frazier, T.; Yin, G.; Huang, X.; Yan, D.F.; Zang, W.J.; et al. Identifying differentially expressed genes under heat stress and developing molecular markers in orchardgrass (Dactylis glomerata L.) through transcriptome analysis. Mol. Ecol. Resour. 2015, 15, 1497-1509. [CrossRef] [PubMed]

29. Yang, X.; Cheng, Y.F.; Deng, C.; Ma, Y.; Wang, Z.W.; Chen, X.H.; Xue, L.B. Comparative transcriptome analysis of eggplant (Solanum melongena L.) and turkey berry (Solanum toroum Sw.): Phylogenomics and disease resistance analysis. BMC Genom. 2014, 15, 412. [CrossRef] [PubMed]

30. Chen, L.Y.; Zhao, S.Y.; Wang, Q.F.; Moody, M.L. Transcriptome sequencing of three Ranunculus species (Ranunculaceae) reveals candidate genes in adaptation from terrestrial to aquatic habitats. Sci. Rep. 2014, 5, 10098. [CrossRef] [PubMed]

31. Guo, J.; Liu, R.; Huang, L.; Zheng, X.M.; Liu, P.L.; Du, Y.S.; Cai, Z.; Zhou, L.; Wei, X.H.; Zhang, F.M.; et al. Widespread and adaptive alterations in genome-wide gene expression associated with ecological divergence of two Oryza species. Mol. Biol. Evol. 2016, 33, 62-78. [CrossRef] [PubMed] 
32. Doyle, J.J. A rapid DNA isolation procedure for small quantities of fresh leaf tissue. Phytochem. Bull. 1987, 19, 11-15.

33. Patel, R.K.; Jain, M. NGSQCToolkit: A toolkit for quality control of next generation sequencing data. PLoS ONE 2012, 7, e30619. [CrossRef] [PubMed]

34. Chevreux, B.; Pfisterer, T.; Drescher, B.; Driesel, A.J.; Müller, W.E.; Wetter, T.; Suhai, S. Using the miraEST assembler for reliable and automated mRNA transcript assembly and SNP detection in sequenced ESTs. Genome Res. 2004, 14, 1147-1159. [CrossRef] [PubMed]

35. Hahn, C.; Bachmann, L.; Chevreux, B. Reconstructing mitochondrial genomes directly from genomic next-generation sequencing reads-a baiting and iterative mapping approach. Nucleic Acids Res. 2013, 41, e129. [CrossRef] [PubMed]

36. Katoh, K.; Misawa, K.; Kuma, K.I.; Miyata, T. MAFFT: A novel method for rapid multiple sequence alignment based on fast fourier transform. Nucleic Acids Res. 2002, 30, 3059-3066. [CrossRef] [PubMed]

37. Wyman, S.K.; Jansen, R.K.; Boore, J.L. Automatic annotation of organellar genomes with DOGMA. Bioinformatics 2004, 20, 3252-3255. [CrossRef] [PubMed]

38. Lohse, M.; Drechsel, O.; Bock, R. OrganellarGenomeDRAW (OGDRAW): A tool for the easy generation of high-quality custom graphical maps of plastid and mitochondrial genomes. Curr. Genet. 2007, 52, 267-274. [CrossRef] [PubMed]

39. Kurtz, S.; Choudhuri, J.V.; Ohlebusch, E.; Schleiermacher, C.; Stoye, J.; Giegerich, R. REPuter: The manifold applications of repeat analysis on a genomic scale. Nucleic Acids Res. 2001, 29, 4633-4642. [CrossRef] [PubMed]

40. Benson, G. Tandem repeats finder: A program to analyze DNA sequences. Nucleic Acids Res. 1999, 27, 573-580. [CrossRef] [PubMed]

41. Li, W.H.; Wu, C.I.; Luo, C.C. A new method for estimating synonymous and nonsynonymous rates of nucleotide substitution considering the relative likelihood of nucleotide and codon changes. Mol. Biol. Evol. 1985, 2, 150-174. [PubMed]

42. Li, W.H. Unbiased estimation of the rates of synonymous and nonsynonymous substitution. J. Mol. Evol. 1993, 36, 96-99. [CrossRef] [PubMed]

43. Pamilo, P.; Bianchi, N. Evolution of the Zfx and Zfy genes: Rates and interdependence between the genes. Mol. Biol. Evol. 1993, 10, 271-281. [PubMed]

44. Yang, Z. PAML 4: Phylogenetic analysis by maximum likelihood. Mol. Biol. Evol. 2007, 24, $1586-1591$. [CrossRef] [PubMed]

45. Wu, M.L.; Lan, S.R.; Cai, B.P.; Chen, S.P.; Chen, H.; Zhou, S.L. The complete chloroplast genome of Guadua angustifolia and comparative analyses of neotropical-paleotropical Bamboos. PLoS ONE 2015, 10, e0143792. [CrossRef] [PubMed]

46. Kumar, S.; Stecher, G.; Tamura, K. MEGA7: Molecular evolutionary genetics analysis version 7.0 for bigger datasets. Mol. Biol. Evol. 2016, 33, 1870-1874. [CrossRef] [PubMed]

47. Ronquist, F.; Huelsenbeck, J.P. MrBayes 3: Bayesian phylogenetic inference under mixed models. Bioinformatics 2003, 19, 1572-1574. [CrossRef] [PubMed]

48. Swofford, D.L. PAUP*: Phylogenetic Analysis Using Parsimony and other Methods, version 4.0; Sinauer Associates: Sunderland, MA, USA, 2002.

49. Darriba, D.; Taboada, G.L.; Doallo, R.; Posada, D. jModelTest 2: More models, new heuristics and parallel computing. Nat. Methods 2012, 9, 772. [CrossRef] [PubMed]

50. Darling, A.C.; Mau, B.; Blattner, F.R.; Perna, N.T. Mauve: Multiple alignment of conserved genomic sequence with rearrangements. Genome Res. 2004, 14, 1394-1403. [CrossRef] [PubMed]

51. Frazer, K.A.; Pachter, L.; Poliakov, A.; Rubin, E.M.; Dubchak, I. VISTA: Computational tools for comparative genomics. Nucleic Acids Res. 2004, 32, w273-w279. [CrossRef] [PubMed]

52. Zhang, Y.J.; Ma, P.F.; Li, D.Z. High-throughput sequencing of six bamboo chloroplast genomes: Phylogenetic implications for temperate woody bamboos (Poaceae: Bambusoideae). PLoS ONE 2011, 6, e20596. [CrossRef] [PubMed]

53. Qian, J.; Song, J.Y.; Gao, H.H.; Zhu, Y.J.; Xu, J.; Pang, X.H.; Yao, H.; Sun, C.; Li, X.E.; Li, C.Y.; et al. The complete chloroplast genome sequence of the medicinal plant Salvia miltiorrhiza. PLoS ONE 2013, 8, e57607. [CrossRef] [PubMed] 
54. Ikemura, T. Codon usage and tRNA content in unicellular and multicellular organisms. Mol. Biol. Evol. 1985, 2, 13-34. [PubMed]

55. Morton, B.R. Chloroplast DNA codon use: Evidence for selection at the $p s b$ A locus based on tRNA availability. J. Mol. Evol. 1993, 37, 273-280. [CrossRef] [PubMed]

56. Sharp, P.; Li, W.H. The rate of synonymous substitution in enterobacterial genes is inversely related to codon usage bias. Mol. Biol. Evol. 1987, 4, 222-230. [PubMed]

57. Kwon, K.C.; Chan, H.T.; León, I.R.; Williams-Carrier, R.; Barkan, A.; Daniell, H. Codon-optimization to enhance expression yields insights into chloroplast translation. Plant Physiol. 2016, 27, 00981. [CrossRef] [PubMed]

58. Bernardi, G.; Bernardi, G. Compositional constraints and genome evolution. J. Mol. Evol. 1986, $24,1-11$. [CrossRef] [PubMed]

59. Suzuki, H.; Morton, B.R. Codon adaptation of plastid genes. PLoS ONE 2016, 11, e0154306. [CrossRef] [PubMed]

60. Asano, T.; Tsudzuki, T.; Takahashi, S.; Shimada, H.; Kadowaki, K.I. Complete nucleotide sequence of the sugarcane (Saccharum officinarum) chloroplast genome: A comparative analysis of four monocot chloroplast genomes. DNA Res. 2004, 11, 93-99. [CrossRef] [PubMed]

61. Timme, R.E.; Kuehl, J.V.; Boore, J.L.; Jansen, R.K. A comparative analysis of the Lactuca and Helianthus (Asteraceae) plastid genomes: Identification of divergent regions and categorization of shared repeats. Am. J. Bot. 2007, 94, 302-312. [CrossRef] [PubMed]

62. Weng, M.L.; Blazier, J.C.; Govindu, M.; Jansen, R.K. Reconstruction of the ancestral plastid genome in Geraniaceae reveals a correlation between genome rearrangements, repeats and nucleotide substitution rates. Mol. Biol. Evol. 2013, 31, 645-659. [CrossRef] [PubMed]

63. Doyle, J.J.; Davis, J.I.; Soreng, R.J.; Garvin, D.; Anderson, M.J. Chloroplast DNA inversions and the origin of the grass family (Poaceae). Proc. Natl. Acad. Sci. USA 1992, 89, 7722-7726. [CrossRef] [PubMed]

64. Ku, C.; Hu, J.M.; Kuo, C.H. Complete plastid genome sequence of the basal asterid Ardisia polysticta Miq. and comparative analyses of asterid plastid genomes. PLoS ONE 2013, 8, e62548. [CrossRef] [PubMed]

65. Maier, R.M.; Neckermann, K.; Igloi, G.L.; Kössel, H. Complete sequence of the maize chloroplast genome: Gene content, hotspots of divergence and fine tuning of genetic information by transcript editing. J. Mol. Biol. 1995, 251, 614-628. [CrossRef] [PubMed]

66. Diekmann, K.; Hodkinson, T.R.; Wolfe, K.H.; van den Bekerom, R.; Dix, P.J.; Barth, S. Complete chloroplast genome sequence of a major allogamous forage species, perennial ryegrass (Lolium perenne L.). DNA Res. 2009, 16, 165-176. [CrossRef] [PubMed]

67. Leebens-Mack, J.; Raubeson, L.A.; Cui, L.; Kuehl, J.V.; Fourcade, M.H.; Chumley, T.W.; Boore, J.L.; Jansen, R.K.; dePamphilis, C.W. Identifying the basal angiosperm node in chloroplast genome phylogenies: Sampling one's way out of the Felsenstein zone. Mol. Biol. Evol. 2005, 22, 1948-1963. [CrossRef] [PubMed]

68. Moore, M.J.; Bell, C.D.; Soltis, P.S.; Soltis, D.E. Using plastid genome-scale data to resolve enigmatic relationships among basal angiosperms. Proc. Natl. Acad. Sci. USA 2007, 104, 19363-19368. [CrossRef] [PubMed]

69. Ma, P.F.; Zhang, Y.X.; Zeng, C.X.; Guo, Z.H.; Li, D.Z. Chloroplast phylogenomic analyses resolve deep-level relationships of an intractable bamboo tribe Arundinarieae (Poaceae). Syst. Biol. 2014, 63, 933-950. [CrossRef] [PubMed]

70. Carbonell-Caballero, J.; Alonso, R.; Ibañez, V.; Terol, J.; Talon, M.; Dopazo, J. A phylogenetic analysis of 34 chloroplast genomes elucidates the relationships between wild and domestic species within the genus Citrus. Mol. Biol. Evol. 2015, 32, 2015-2035. [CrossRef] [PubMed]

71. Reboud, X.; Zeyl, C. Organelle inheritance in plants. Heredity 1994, 72, 132-140. [CrossRef]

72. Feng, J.J.; Jiang, D.C.; Shang, H.Y.; Dong, M.; Wang, G.N.; He, X.Y.; Zhao, C.; Mao, K. Barcoding poplars (Populus L.) from western China. PLoS ONE 2013, 8, e71710. [CrossRef] [PubMed]

73. Degnan, J.H.; Rosenberg, N.A. Gene tree discordance, phylogenetic inference and the multispecies coalescent. Trends Ecol. Evol. 2009, 24, 332-340. [CrossRef] [PubMed]

74. Acosta, M.C.; Premoli, A.C. Evidence of chloroplast capture in South American Nothofagus (subgenus Nothofagus, Nothofagaceae). Mol. Phylogenet. Evol. 2010, 54, 235-242. [CrossRef] [PubMed] 
75. Pelser, P.B.; Kennedy, A.H.; Tepe, E.J.; Shidler, J.B.; Nordenstam, B.; Kadereit, J.W.; Watson, L.E. Patterns and causes of incongruence between plastid and nuclear Senecioneae (Asteraceae) phylogenies. Am. J. Bot. 2010, 97, 856-873. [CrossRef] [PubMed]

76. Liu, X. Phylogenetic and taxonomic status analyses of the abaso section in populus from multiple nuclear genes and plastid fragments reveal new insights into the North America origin of Populus. Front. Plant Sci. 2016, 7, 2022. [CrossRef] [PubMed]

77. Alvarez, I.; Wendel, J.F. Ribosomal ITS sequences and plant phylogenetic inference. Mol. Phylogenet. Evol. 2003, 29, 417-434. [CrossRef]

78. Hu, S.; Sablok, G.; Wang, B.; Qu, D.; Barbaro, E.; Viola, R.; Li, M.A.; Varotto, C. Plastome organization and evolution of chloroplast genes in Cardamine species adapted to contrasting habitats. BMC Genom. 2015, 16, 306. [CrossRef] [PubMed]

79. Ometto, L.; Li, M.; Bresadola, L.; Varotto, C. Rates of evolution in stress-related genes are associated with habitat preference in two Cardamine lineages. BMC Evol. Biol. 2012, 12, 7. [CrossRef] [PubMed]

80. Morinaga, S.I.; Nagano, A.J.; Miyazaki, S.; Kubo, M.; Demura, T.; Fukuda, H.; Sakai, S.; Hasebe, M. Ecogenomics of cleistogamous and chasmogamous flowering: Genome-wide gene expression patterns from cross-species microarray analysis in Cardamine kokaiensis (Brassicaceae). J. Ecol. 2008, 96, 1086-1097. [CrossRef]

81. Streb, P.; Shang, W.; Feierabend, J.; Bligny, R. Divergent strategies of photoprotection in high-mountain plants. Planta 1998, 207, 313-324. [CrossRef]

82. Germino, M.J.; Smith, W.K. High resistance to low-temperature photo inhibition in two alpine, snowbank species. Physiol. Plant. 2000, 110, 89-95. [CrossRef]

83. Frohnmeyer, H.; Staiger, D. Ultraviolet-B radiation-mediated responses in plants. Balancing damage and protection. Plant Physiol. 2003, 133, 1420-1428. [CrossRef] [PubMed]

84. Streb, P.; Aubert, S.; Gout, E.; Bligny, R. Cold and light induced changes of metabolite and antioxidant levels in two high mountain plant species Soldanella alpina and Ranunculus glacialis and a lowland species Pisum sativum. Physiol. Plant. 2003, 118, 96-104. [CrossRef] [PubMed]

85. Ikeda, H.; Fujii, N.; Setoguchi, H. Molecular evolution of phytochromes in Cardamine nipponica (Brassicaceae) suggests the involvement of PHYE in local adaptation. Genetics 2009, 182, 603-614. [CrossRef] [PubMed]

86. Tomoko, O. Synonymous and nonsynonymous substitutions in mammalian genes and the nearly neutral theory. J. Mol. Evol. 1995, 40, 56-63. [CrossRef]

87. McInerney, J.O. The causes of protein evolutionary rate variation. Trends Ecol. Evol. 2006, 21, $230-232$. [CrossRef] [PubMed]

88. Sugiura, C.; Kobayashi, Y.; Aoki, S.; Sugita, C.; Sugita, M. Complete chloroplast DNA sequence of the moss Physcomitrella patens: Evidence for the loss and relocation of rpoA from the chloroplast to the nucleus. Nucleic Acids Res. 2003, 31, 5324-5331. [CrossRef] [PubMed]

89. Kim, K.J.; Lee, H.L. Complete chloroplast genome sequences from Korean ginseng (Panax schinseng Nees) and comparative analysis of sequence evolution among 17 vascular plants. DNA Res. 2004, 11, 247-261. [CrossRef] [PubMed]

90. Kode, V.; Mudd, E.A.; Iamtham, S.; Day, A. The tobacco plastid $a c c D$ gene is essential and is required for leaf development. Plant J. 2005, 44, 237-244. [CrossRef] [PubMed]

91. Madoka, Y.; Tomizawa, K.I.; Mizoi, J.; Nishida, I.; Nagano, Y.; Sasaki, Y. Chloroplast transformation with modified $a c c D$ operon increases acetyl-CoA carboxylase and causes extension of leaf longevity and increase in seed yield in tobacco. Plant Cell Physiol. 2002, 43, 1518-1525. [CrossRef] [PubMed]

(C) 2017 by the authors. Licensee MDPI, Basel, Switzerland. This article is an open access article distributed under the terms and conditions of the Creative Commons Attribution (CC BY) license (http://creativecommons.org/licenses/by/4.0/). 